\title{
Genome-wide dynamic transcriptional profiling in clostridium beijerinckii NCIMB 8052 using single- nucleotide resolution RNA-Seq
}

\author{
Yi Wang ${ }^{1,2}$, Xiangzhen Li, ${ }^{3,4}$, Yuejian Mao ${ }^{3}$ and Hans P Blaschek ${ }^{2,5,6^{*}}$
}

\begin{abstract}
Background: Clostridium beijerinckii is a prominent solvent-producing microbe that has great potential for biofuel and chemical industries. Although transcriptional analysis is essential to understand gene functions and regulation and thus elucidate proper strategies for further strain improvement, limited information is available on the genome-wide transcriptional analysis for C. beijerinckii.

Results: The genome-wide transcriptional dynamics of C. beijerinckii NCIMB 8052 over a batch fermentation process was investigated using high-throughput RNA-Seq technology. The gene expression profiles indicated that the glycolysis genes were highly expressed throughout the fermentation, with comparatively more active expression during acidogenesis phase. The expression of acid formation genes was down-regulated at the onset of solvent formation, in accordance with the metabolic pathway shift from acidogenesis to solventogenesis. The acetone formation gene $(a d c)$, as a part of the sol operon, exhibited highly-coordinated expression with the other sol genes. Out of the > 20 genes encoding alcohol dehydrogenase in C. beijerinckii, Cbei_1722 and Cbei_2181 were highly up-regulated at the onset of solventogenesis, corresponding to their key roles in primary alcohol production. Most sporulation genes in C. beijerinckii 8052 demonstrated similar temporal expression patterns to those observed in B. subtilis and C. acetobutylicum, while sporulation sigma factor genes sigE and sig $G$ exhibited accelerated and stronger expression in C. beijerinckii 8052, which is consistent with the more rapid forespore and endspore development in this strain. Global expression patterns for specific gene functional classes were examined using self-organizing map analysis. The genes associated with specific functional classes demonstrated global expression profiles corresponding to the cell physiological variation and metabolic pathway switch.
\end{abstract}

Conclusions: The results from this work provided insights for further C. beijerinckii strain improvement employing system biology-based strategies and metabolic engineering approaches.

\section{Background}

Solvents such as acetone, butanol and ethanol (ABE) produced through microbial fermentation represent important potential renewable fuels and chemicals [1]. Clostridium acetobutylicum and C. beijerinckii are among the prominent solvent-producing species. C. beijerinckii exhibits a broader substrate range and optimum $\mathrm{pH}$ for growth and solvent production [2]; thus it may have greater potential for biosolvent production than C. acetobutylicum.

\footnotetext{
* Correspondence: blaschek@illinois.edu

${ }^{2}$ Institute for Genomic Biology, University of Illinois at Urbana-Champaign, Urbana, IL 61801, USA

Full list of author information is available at the end of the article
}

The genome of C. beijerinckii NCIMB 8052 was sequenced by the DOE Joint Genome Institute in 2007. The genome size is $6.0 \mathrm{Mb}$, which is $50 \%$ larger than that of C. acetobutylicum ATCC 824. The C. beijerinckii 8052 solvent-producing genes are all located on the chromosome, as opposed to the location of these genes on a megaplasmid in C. acetobutylicum 824. Transcriptional analysis is essential to understand gene functions and regulation and thus elucidate proper strategies for further strain improvement. While global gene expression patterns for C. acetobutylicum have been studied extensively [3-9], limited information is available on the genome-wide transcriptional analysis for C. beijerinckii [10]. RNA-Seq is based on the high-throughput DNA sequencing technology and

\section{Biomed Central}


provides an approach to profile and quantify gene expression to an unprecedented resolution and depth [11-14]. RNA-Seq technology has several advantages over DNA microarray methods for transcriptional analysis. First, microarray and other hybridization techniques exhibit a relatively low dynamic range for the detection of transcriptional levels due to background, saturation and poor sensitivity for gene expression at very low or high levels [15], while RNA-Seq does not have an upper limit for quantification and has a larger dynamic range of expression levels. In addition, when compared to microarray-based approaches, RNA-Seq has very low background noise because DNA sequence reads can be unambiguously mapped to unique regions along the genome [16]. Several recent studies have proven that RNA-Seq is a powerful tool for transcriptional analysis $[12,17,18]$. In this study, a genome-wide transcriptional analysis of $C$. beijerinckii 8052 over the course of a batch fermentation was described from an unbiased perspective using RNA-Seq technology. The findings from this work provided insights for further $C$. beijerinckii strain improvement employing system biology-based strategies and metabolic engineering. Furthermore, this work is also an essential methodology reference for conducting transcriptional analysis employing next-generation sequencing technology.

\section{Results and discussion}

\section{Growth kinetics and ABE fermentation}

The C. beijerinckii 8052 growth response in the batch fermentation is illustrated in Figure 1A (see also [19]). The fermentation shifted from acidogenesis to solventogenesis at approximately 4.5-8 h. Production of solvents was detected at between 4.5-6.5 h after the start of fermentation, which corresponded to the late exponential growth phase. Butanol continued to increase throughout the stationary phase (Figure 1B). Samples for RNA isolation were collected at various time points during acidogenesis (2 and $4.5 \mathrm{~h}$ ) and solventogenesis (after $6.5 \mathrm{~h}$ ) (Figure 1A). These samples were sequenced for dynamic transcriptional profiling for C. beijerinckii 8052.

\section{Overall gene transcription dynamics}

The 75-nt sequence reads were mapped to the $C$. beijerinckii 8052 genome. Only those reads that mapped unambiguously to the genome were used for further analyses (Table 1). Based on RNA-Seq sequence data, 3386 out of $5020(67.4 \%)$ protein-coding genes had detectable expression in all six sampling time points, while 78 demonstrated no transcripts over all six time points, and are likely silent [19].

On the other hand, there were some genes that demonstrated little variation in expression levels throughout the entire fermentation process, and they are regarded as putative housekeeping genes (HKGs). In this study, 177
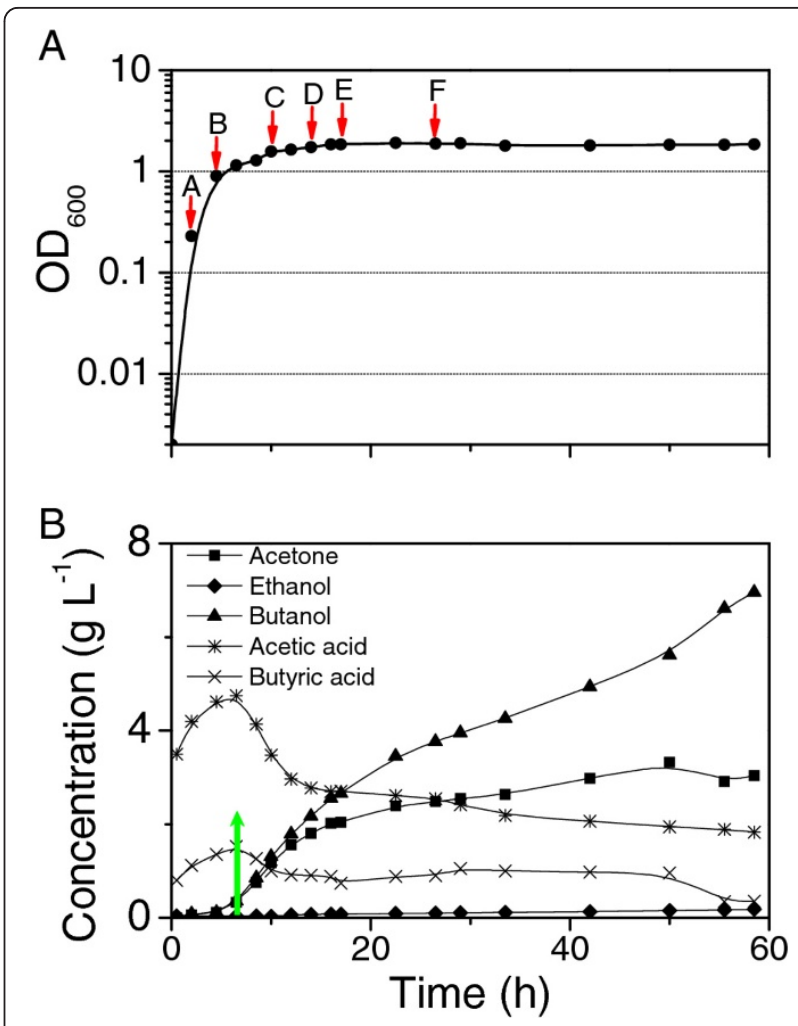

Figure 1 Fermentation kinetics of C. beijerinckii 8052 batch culture. (A) Cell growth curve with sampling points for RNA-Seq indicated by red arrows. (B) Solvents and acids production over time with the onset of solvent production indicated by a green arrow.

protein-coding genes were identified as putative HKGs with the lowest coefficient of variation (CV) in RPKM (reads/Kb/Million, see the Methods section) values among all the sampling points [19]. For accurate gene expression analysis, normalization of gene expression against HKGs is generally required. In the qRT-PCR test in this work, a putative HKG (Cbei_2428, encoding peptidase T) with highly constant expression levels across all six sampling points was selected as the endogenous control gene.

Detrended Correspondence Analysis (DCA) was conducted on the RNA-Seq data to generate overall dynamic transcription profiles throughout the batch fermentation process. DCA is an ordination technique that uses detrending to remove the 'arch effect' usually existing in correspondence analysis [20]. As shown in Figure 2A, an obvious temporal variation trend was observed for the overall gene transcription. While the first three samples which were from the exponential and transition phases presented both significant first detrended correspondence (DC1, explained $40.6 \%$ of detrended correspondence) and second detrended correspondence (DC2, explained 15.2\% of detrended correspondence), the last three samples 
Table 1 Summary of RNA-Seq sequencing and data analysis results

\begin{tabular}{|c|c|c|c|c|c|c|c|}
\hline Sample & A & B & C & D & $\mathrm{E}$ & $\mathrm{F}^{*}$ & Total \\
\hline Time collected (h) & 2 & 4.5 & 10 & 14 & 17 & 26.5 & \\
\hline Total number of reads & 8988633 & 9457480 & 8011531 & 8448929 & 10363535 & 38574501 & 83844609 \\
\hline No. of reads mapped & 8473125 & 9037616 & 7514804 & 7730815 & 9842491 & 37676913 & 80275764 \\
\hline $\begin{array}{l}\text { No. of reads unambiguously } \\
\text { mapped }\end{array}$ & 6776544 & 7274568 & 6096405 & 6189652 & 8096169 & 35027722 & 69461060 \\
\hline $\begin{array}{l}\text { No. of genes with detectable } \\
\text { expression** }\end{array}$ & 4219 & 4082 & 4496 & 4453 & 4487 & 4750 & 5024 \\
\hline $\begin{array}{c}\text { Range in expression levels } \\
\text { (RPKM) }\end{array}$ & $\begin{array}{l}3.2 \times 10^{-1} \sim \\
2.5 \times 10^{4}\end{array}$ & $\begin{array}{l}5.8 \times 10^{-2} \sim \\
6.0 \times 10^{4}\end{array}$ & $\begin{array}{l}4.5 \times 10^{-2} \sim \\
2.5 \times 10^{4}\end{array}$ & $\begin{array}{l}7.0 \times 10^{-2} \sim \\
9.0 \times 10^{4}\end{array}$ & $\begin{array}{l}1.0 \times 10^{-1} \sim \\
8.6 \times 10^{4}\end{array}$ & $\begin{array}{l}3.6 \times 10^{-2} \sim \\
9.8 \times 10^{4}\end{array}$ & $\begin{array}{l}3.6 \times 10^{-2} \sim \\
9.8 \times 10^{4}\end{array}$ \\
\hline
\end{tabular}

*Sample F was sequenced with 1 sample/lane, while samples A-E with 2 samples/lane. See Methods section for more details; ** Pseudogenes included

which were from stationary phase demonstrated only significant DC2 but little DC1. The temporal variation trend of the overall gene expression is consistent with different

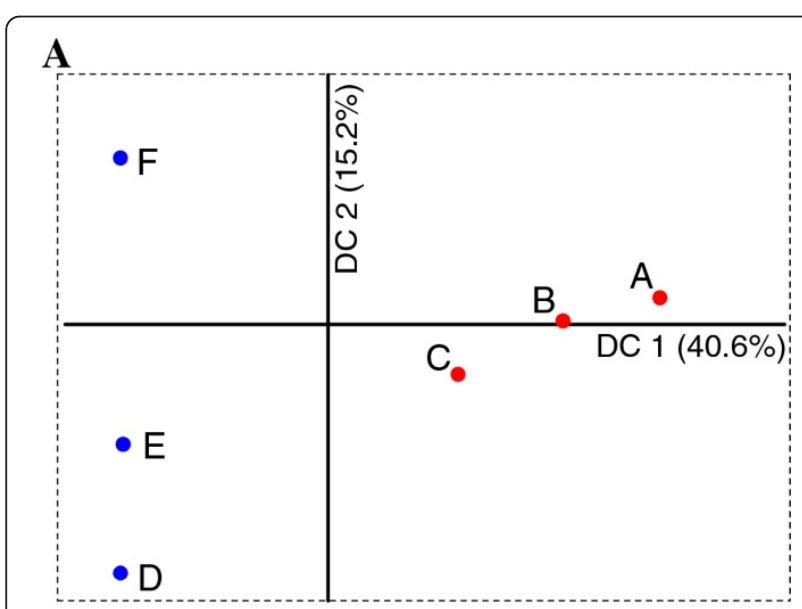

\section{B}

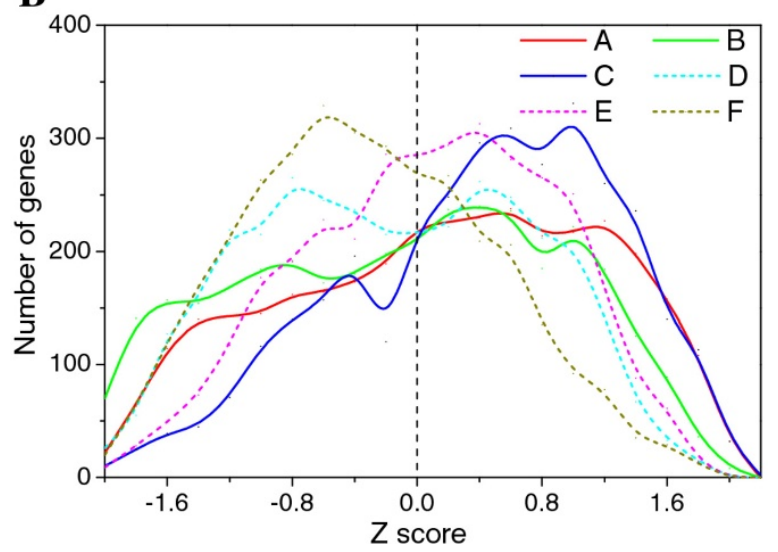

Figure 2 Overall gene transcription profiles during the fermentation based on RNA-Seq data. (A) Detrended

Correspondence Analysis (DCA). Sampling points from exponential phase and transition phase $(A-C)$ were indicated in red, while points from stationary phase (D-F) were indicated in blue. (B) Gene distribution based on Z-score analysis. Samples A-F were indicated by different line styles and colors. cell physiological states during transition from acidogenesis to solventogenesis.

A Z-score analysis was conducted to investigate the overall gene expression pattern at each time point. Z-score measures the number of standard deviations that a gene expression in a specific sample is from the mean expression of this gene over all samples. It is a dimensionless quantity derived by subtracting the mean expression of a specific gene over all samples from the individual expression level in a specific sample and then dividing the difference by the standard deviation $[18,21]$. The results demonstrated temporally dynamic patterns over the course of cell growth and batch fermentation (Figure 2B). Generally, during exponential and early stationary phases $(2-10 \mathrm{~h})$, more genes shifted towards higher expression values (to the right on Figure 2B), while during late stationary phases, more genes shifted to lower expression levels (to the left on Figure 2B). A list of genes whose Z-score was $>1.7$ in each sample is summarized in Additional file 1: Table S1. The highly expressed gene categories were different at different time points during the course of the fermentation. For example, translation related genes (COG J) were predominant (49 out of total 141 genes in this list) in sample A (at $2 \mathrm{~h}$ ), indicating fast protein synthesis during this growth stage; while signal transduction mechanism involved genes (COG T) were overrepresented at $10 \mathrm{~h}$, indicating the cellular reaction to the environmental changes.

The expression of different genes in a specific sample can be compared by plotting $\log _{2}$-transformed RPKM values of all genes against their loci along the genome (Figure 3).

Sample B represented the beginning of the transition from acidogenesis to solventogenesis. In this sample, among the highest expressed genes, besides the genes encoding hypothetical proteins (31 out of the top 100 highest expressed), 12 are ribosomal protein genes, indicating active protein synthesis machinery in the cell at this time point. In addition, genes involved in acid and solvent 


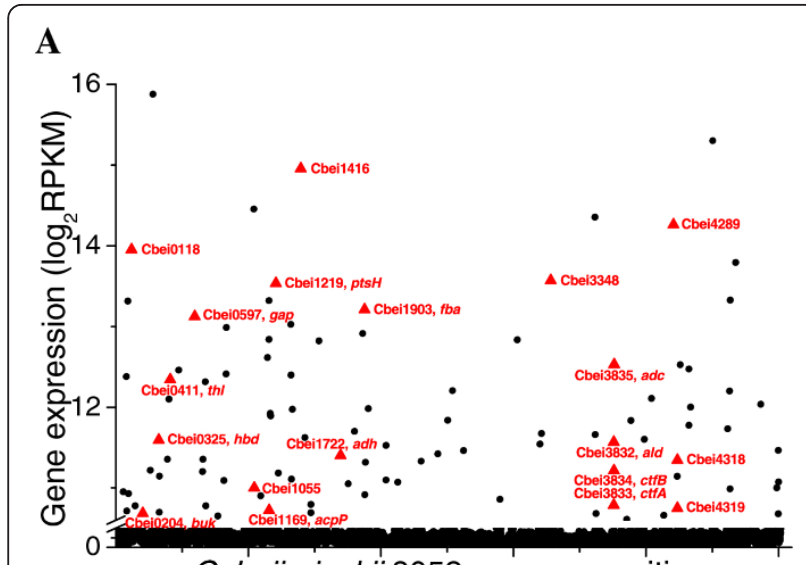

C. beijerinckii 8052 genome position

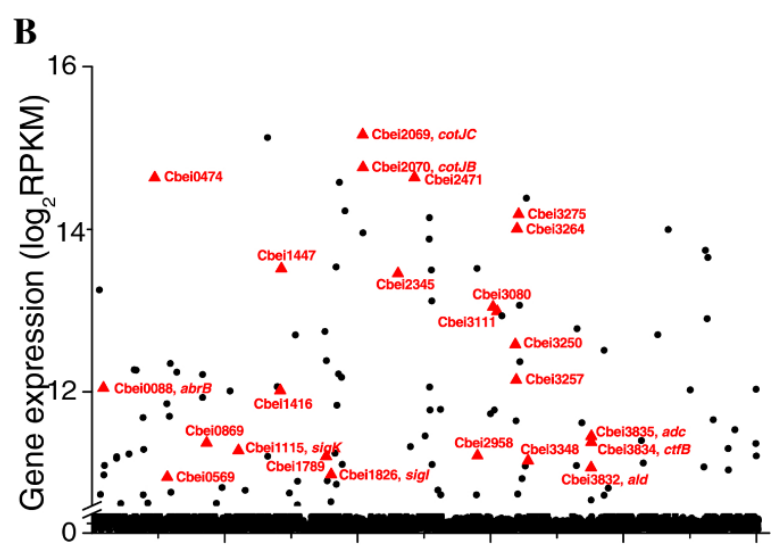

C. beijerinckii 8052 genome position

Figure 3 Identification of highly expressed genes in samples B and $D$ by plotting the $\log _{2}$-scaled gene expression values against the gene loci through the genome. (A) Plot of gene expression level $\left(\log _{2}(\mathrm{RPKM})\right)$ against the gene locus through the genome in sample B (at 4.5 h). (B) Plot of gene expression level $\left(\log _{2}(\mathrm{RPKM})\right)$ against the gene locus through the genome in sample $D$ (at $14 \mathrm{~h}$ ). The highly expressed genes involved in the main metabolic pathways during the fermentation were labeled with larger triangles.

formation were detected as highly expressed, including adc (Cbei_3835), thl (Cbei_0411), hbd (Cbei_0325), ald (Cbei_3832), adh (Cbei_1722), ctfB (Cbei_3834), ctfA (Cbei_3833) and buk (Cbei_0204). Highly expressed genes also included those encoding proteins that mediate electron transfer, such as Cbei_1416 (rubrerythrin), Cbei_0118, Cbei_3348 (desulfoferrodoxin), Cbei_4318, Cbei_4319 (flavodoxin), and those genes related to cell motility (Cbei_4289), phosphotransferase system (PTS) for sugar uptake (Cbei_1219) and glycolytic activity (Cbei_1903, fba and Cbei_0597, gap) (Figure 3 and Additional file 2: Table S2). The time frame of sample D was consistent with the transition to non-active growth and clostridial spore formation. While the solventogenesis genes $(a d c, a l d, c t f B, c t f A)$ and several ferredoxin activity protein encoding genes (Cbei_3257,_3348 and_0569) were still actively expressed at this stage (Figure 3 and Additional file 2: Table S2), genes encoding sporulation-related proteins demonstrated the highest transcriptional activities. These genes included those encoding spore coat proteins (Cbei_2069, cotJC and Cbei_2070, $\operatorname{cotJB}$ ), small acid-soluble spore proteins (Cbei_2471, _0474,_3275,_3264,_1447,_2345,_3080,_3111 and _3250), AbrB family transcriptional regulator (Cbei_0088, annotated as AbrB family stage $\mathrm{V}$ sporulation protein $\mathrm{T}$ in C. acetobutylicum) and sporulation sigma factor SigK (Cbei_1115).

It is interesting that the hypothetical genes account for a large fraction of the highly expressed genes (in both samples B and D presented above). As we mentioned previously [19], the genome annotation for C. beijerinckii 8052 is far from completed. Many of the hypothetical genes predicted by computational analysis algorithms may have important functions for the cell activities. The RNASeq results herein provided useful references for future studies in defining the specific functions of these genes.

\section{Expression of primary metabolic genes Glycolysis genes}

Generally, the glycolysis genes encoding the pathway for conversion of glucose to pyruvate were expressed at high levels throughout the entire fermentation process (Figure 4A). Comparatively, the expression of most of these genes decreased slightly after entering the stationary phase, down-regulated by 2 - to 4 -fold. In C. beijerinckii 8052, three genes (Cbei_0584, Cbei_0998 and Cbei_4852) are annotated as encoding 6-phosphofructokinase (pfk). While Cbei_0584 and _4852 were downregulated 2.3- and 2.7-fold respectively after entering stationary phase, Cbei_0998 was up-regulated 3.8-fold at time point $\mathrm{C}$ and expressed at higher levels throughout stationary phase. Cbei_0485, Cbei_1412 and Cbei_4851 are all annotated as encoding pyruvate kinase (pyk). While Cbei_0485 and_4851 decreased by 2.5 -fold after entering stationary phase, Cbei_1412 was expressed at a higher level throughout stationary phase when compared to the exponential phase. These observations imply that different allelic genes may be induced at different specific stages and play different roles during the fermentation process. The expression patterns of glycolysis genes in this study are similar to those found for C. beijerinckii 8052 in Shi and Blaschek (2008) [10]. While in a time course transcriptional analysis of C. acetobutylicum 824 during a batch fermentation, most of the glycolysis genes showed higher expression during stationary-phase [5].

\section{Acidogenesis and solventogenesis genes}

The acetate formation genes encoding phosphotransacetylase (pta, Cbei_1164) and acetate kinase (ack, Cbei_1165) 
and the butyrate formation genes encoding phosphate butyryltransferase ( $p t b$, Cbei_0203) and butyrate kinase (buk, Cbei_0204) were up-regulated during the acidogenesis phase and peaked at time point $\mathrm{B}$, and declined 2- to 4-fold at the onset of solvent formation (Figure 4A). Based on the sequencing data, the $p t a-a c k$ and $p t b-b u k$ gene operon structures were identified [19]. The coordinated expression patterns of these two gene clusters further confirmed this transcriptional organization. Expression of genes encoding proteins involved in butyryl coenzyme A (butyryl-CoA) formation was induced early during the acidogenesis phase, and remained at high levels after cells entered stationary phase (time point $C$ ), and afterwards decreased 3-to 7-fold at late stationary phase, although the absolute transcription level was still high (Figure 4A).

The product of the thlA (Cbei_0411) in C. beijerinckii has $77 \%$ amino acid sequence identity to the product of thlA (CAC2873) in C. acetobutylicum, and the product of a second thiolase gene (thlB, Cbei_3630) shows $90 \%$ amino acid sequence identity to that of thlB (or thil) in C. acetobutylicum (CAP0078). A transcriptional analysis with qRT-PCR for continuous cultures of $C$. acetobutylicum indicated that the level of $t h l B$ transcripts was much lower compared to the level of $t h l A$ transcript, and the expression of thlB was maximal at about 10 to $15 \mathrm{~h}$ after induction of solvent formation [22]. Whereas another transcriptional analysis for continuous cultures of C. acetobutylicum showed that $t h l B$ was highly induced only during the transition state from acidogenesis to solventogenesis [23]. In this study, the expression level of $t h l B$, although much lower than that of $t h l A$, was found to be maximal in late stationary phase (time points $\mathrm{E}$ and F), which is around 10 to $20 \mathrm{~h}$ after onset of solventogenesis (Figure 1). While thlA is involved in the primary metabolism of acid and solvent formation, the physiological function of thlB warrants further study. In the $C$. beijerinckii 8052 genome, there are different genes encoding for isoenzymes active in specific stages and playing different roles. Transcriptomic analysis leads to insights for further biochemical characterization of the isoenzymes properties and functions.

In C. acetobutylicum 824, the genes adhE (bifunctional acetaldehyde-CoA/alcohol dehydrogenase, CA_P0162), ctfA (acetoacetyl-CoA: acetate/butyrate-CoA transferase subunit A, CA_P0163) and ctfB (acetoacetyl-CoA: acetate/ butyrate-CoA transferase subunit B, CA_P0164) are located in the sol (solvent formation) operon on the megaplasmid pSOL1, while adc (acetoacetate decarboxylase, CA_P0165) is organized in a monocistronic operon in the opposite direction [24-26]. The regulation of $a d c$ was believed to differ from that of the sol operon, and the expression of $a d c$ was reported to be initiated earlier than the sol operon in both batch and continuous cultures of C. acetobutylicum [5,23,27-29]. Based on our sequencing data, a sol operon organized in the order of ald (Cbei_3832, encoding aldehyde dehydrogenase)-ctfA (Cbei_3833)-ctfB (Cbei_3834)-adc (Cbei_3835) was revealed in C. beijerinckii 8052 [19]. Consistent with this transcriptomic organization, coordinated expression was observed for the sol operon genes. Their expression was up-regulated at the onset of solventogenesis phase and maintained at high levels during the stationary phase (Figure 4A).

Two iron-containing alcohol dehydrogenase genes adhA (GenBank: AF497741.2) and adhB (GenBank: AF497742.1) were previously characterized in the solvent-producing strain C. beijerinckii NRRL B592 [10,30]. The enzymes encoded by both genes were classified as primary alcohol dehydrogenases, which catalyze the reaction for primary alcohol (that is, butanol and ethanol, but not isopropanol) production [30]. The product of Cbei_2181 in C. beijerinckii 8052 exists 99\% and 97\% amino acid sequence identity to that of $a d h A$ and $a d h B$, and the product of Cbei_1722 has $97 \%$ and $94 \%$ amino acid sequence identity to that of $a d h B$ and $a d h A$, respectively. Cbei_2181 and_1722 may play key roles during primary alcohol production in C. beijerinckii 8052. Both genes were induced to high levels (9 and 4fold up respectively) when the fermentation transitioned from the acid production phase to the solvent production phase (time point B), and then decreased. Similar transient up-regulation of $a d h$ genes and enzymes associated with active solvent production was previously reported for C. beijerinckii NRRL B592 and C. acetobutylicum 824 [30-32].

There are 20 annotated alcohol dehydrogenase genes in C. beijerinckii 8052, suggesting the great potential for solvent production of this microorganism. Most of these genes were induced early during the acidogenesis phase and expressed at high levels throughout the solvent production process, although some of them did not have detectable expression at some specific time points (Additional file 3: Table S3). The specific functions of different alcohol dehydrogenase genes associated with C. beijerinckii require further investigation.

\section{Sporulation genes}

Production of solvents was first detected between 4.5-6.5 $\mathrm{h}$ after the start of fermentation, which corresponded to the late exponential growth phase. The initiation of sporulation in C. beijerinckii 8052 was concurrent with the onset of solventogenesis.

In $B$. subtilis, the gene spoOH encodes the earliest acting sigma factor associated with sporulation, $\sigma^{\mathrm{H}}$, which regulates the early sporulation genes, including spoOA and sigF operon [33]. The phosphorylated Spo0A (Spo0A P) by phosphorelay system indirectly induces $s p o O H$ transcription by repressing $a b r B$ transcription [34]. In clostridia, no similar phosphorelay components and regulation system 

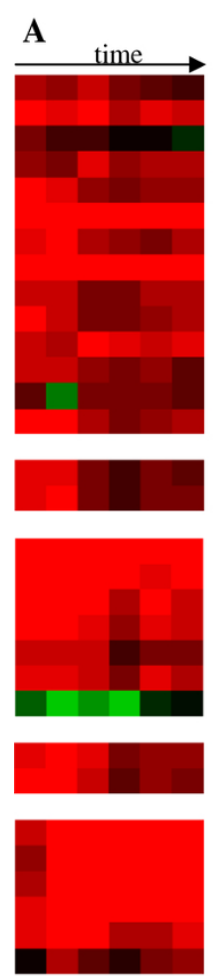

B
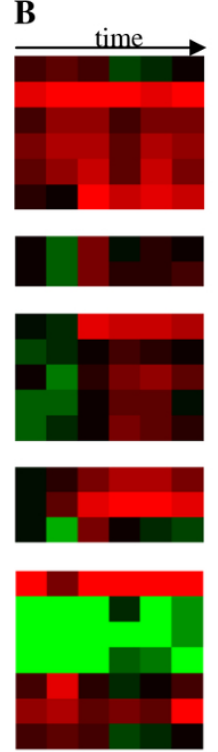

Glycolysis genes

Cbei_4895, glcK

Cbei_0341,pgi

Cbei_0584, pfk

Cbei_0998,pfk

Cbei_4852, pfk

Cbei_1903, fba

Cbei_0599, tpi

Cbei_0597, gap

Cbei_0598,pgk

Cbei_0600, pgm

Cbei_0602, eno

Cbei_0485, pyk

Cbei_1412, pyk

Cbei_4851, pyk

Acetate formation genes

Cbei_1164,pta

Cbei_1165, ack

Butyryl-CoA formation genes

Cbei_0411, thlA

Cbei_0325, $h b d$

Cbei_0321, crt

Cbei_0322, bcd

Cbei_0324, etfA

Cbei_0323, etfB

Cbei 3630, thlB

Butyrate formation genes

Cbei_0203, ptb

Cbei_0204, buk

Solventogenesis genes

Cbei_3832, ald

Cbei_3833, ctfA

Cbei_3834, ctfB

Cbei_3835, adc

Cbei_1722, adh

Cbei_2181, adh

arly sporulation genes

Cbei_0135, spoOH

Cbei_1712, spo0A

Cbei_0814, sigF

Cbei_0813, spoIIAB

Cbei_0812, spoIIAA

Cbei_0097, spoIIE

sigE operon genes

Cbei_1119, spoIIGA

Cbei_1120, sigE

$\operatorname{sig} G$ and $\sigma^{\mathrm{G}}$-regulated genes

Cbei_1121, sigG

Cbei 1711, spolVB

Cbei 0815, spoVAC

Cbei_0816, spoVAD

Cbei_0817, spoVAE

spoIIID, sigK and spoIVFB

Cbei_0424, spoIIID

Cbei_1115, sigK

Cbei_0501, putative spoIVFB

Putative $a b r B$ genes and $s p o O H$

Cbei_0088, abrB

Cbei_2219, abrB

Cbei_2270, $a b r B$

Cbei_3199, abrB

Cbei_3375, abrB

Cbei_4885, abrB

Cbei_0135, spoOH
(B, continued)

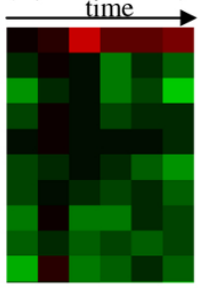

Putative sensory kinase genes

Cbei_0017

Cbei_0361

Cbei_0555

Cbei_0710

Cbei_1553

Cbei_2435

Cbei_2515

Cbei_2732

Cbei_2786

Cbei_3169

C

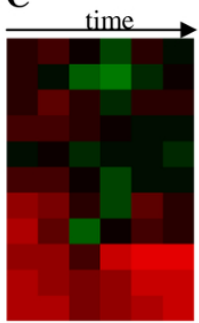

Cell motility genes-

Cbei_4312

Cbei_4311, cheW

Cbei_4310, cheD

Cbei_4309, cheB

Cbei_4308, cheR

Cbei_4307, cheA

Cbei 4306, che C

Cbei_4305, cheY

Cbei_4304, chew

Cbei_4303, fliM

Cbei_4302, fliY

Cell motility genes-2

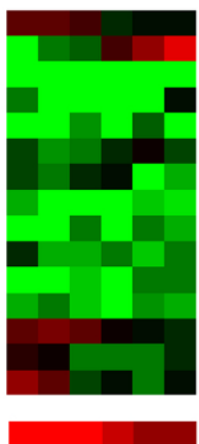

Cbei_0755, cheW

Cbei_3954, cheW

Cbei_4018, cheW

Cbei_4184, cheW

Cbei_4822, cheW

Cbei_4180, cheB

Cbei_4826, cheB

Cbei_4181, cheR

Cbei_4827, cheR

Cbei_4019, cheA

Cbei_4183, cheA

Cbei_4829, cheA

Cbei_4958, cheC

Cbei_4271, flgB

Cbei_4270, flgC

Putative quorum sensing gene

Cbei_1237, luxS

Sugar transport genes

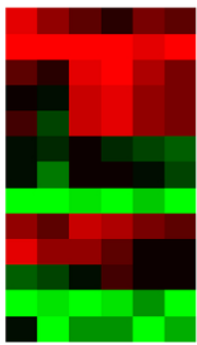

Cbei_0196,ptsI

Cbei_1219, ptsH

Cbei_0711, manIIAB

Cbei_0712, manIIC

Cbei_0713, manIID

Cbei_0751

Cbei_3273

Cbei 3772

Cbei_4532

Cbei_4533

Cbei_4705

Cbei_4977

Cbei_4982

Putative granulose formation genes

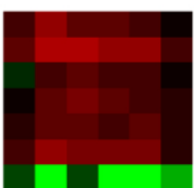

Cbei_4904, glgD

Cbei_4905, glgC

Cbei_4906

Cbei_4907,glgP

Cbei_4908, glgA

Cbei_4909

Cbei_4295, csrA

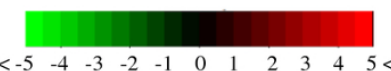

Figure 4 Time course expression profiles of important genes during the batch fermentation process. (A) Genes related to glycolysis, acidogenesis and solventogenesis. (B) Sporulation genes, putative abrB genes and putative sensory kinase genes. (C) Genes related to cell motility, putative quorum sensing, sugar transport and granulose formation.

have been observed. It have been reported that in $C$. acetobutylicum, spoOH and spoOA were both constitutively expressed at constant levels throughout the growth cycle, and the amount of $s p o O H$ transcript was much lower than that of spoOA [34]. While a recent time-course transcriptional analysis of $C$. acetobutylicum indicated that spo0A was induced at the onset of sporulation and kept at high levels throughout the stationary phase [5]. In this study, the expression of $\mathrm{spoOH}$ (Cbei_0135) was constant from time points A-C, but was down-regulated 5.4-fold 
later during the fermentation (Figure 4B). The expression of spoOA (Cbei_1712) was induced early during the acidogenesis phase, and elevated by 2.2 -fold during the transition phase and the onset of solventogenesis (time points $\mathrm{B}$ and $\mathrm{C}$ ), after which the expression was slightly down-regulated (1.7-fold). Comparatively, the transcription level of spoOA was much higher than that of spoOH (Figure 4B). Putative $\sigma^{\mathrm{H}}$-dependent promoter and SpoOA-binding motif (0A box) have been identified upstream of the spoOA gene in C. beijerinckii 8052 [35].

It is well established that $s p o O A$ is the master regulator for sporulation events in both bacilli and clostridia [5,34]. Phosphorylated spoOA has been reported to induce various targets, including the solventogenic operon and multiple sporulation sigma factor genes in C. acetobutylicum $[3,36,37]$. 0A boxes were also identified upstream of the operons related to chemotaxis/motility, suggesting the possible negative regulation of Spo0A on the expression of chemotaxis/motility genes [37-39]. A previous study involving insertional inactivation of spoOA indicated that Spo0A does also control the formation of solvents, spores and granulose in C. beijerinckii [40]. A recently developed spoOA mutant of $C$. beijerinckii 8052 exhibited an asporogenous and non-septating phenotype [41]

The sigF operon (spoIIAA-spoIIAB-sigF) encodes the anti-anti-sigma factor (SpoIIAA), the anti-sigma factor $\left(\right.$ SpoIIAB) and the sigma factor $\sigma^{\mathrm{F}}$. In the "crisscross regulation" system of $B$. subtilis, both $\sigma^{\mathrm{H}}$ and Spo0A $\sim \mathrm{P}$ are required for the expression of the genes in this operon [42]. In this study, the sigF operon genes were induced before the onset of sporulation (time point B), and kept coordinated and high-regulated throughout the fermentation (Figure 4B).

SpoIIE is a phosphatase required for regulating the dephosphorylation of SpoIIAA, which helps to release the $\sigma^{\mathrm{F}}$ from SpoIIAB by forming an ADP-SpoIIABSpoIIAA complex [43]. In B. subtilis, expression of spoIIE starts about $1 \mathrm{~h}$ after the onset of sporulation, and peaks approximately $1 \mathrm{~h}$ later [44]. In the present study, high expression of spoIIE (Cbei_0097) in C. beijerinckii 8052 was induced at time point $\mathrm{C}$ (51.3-fold up-regulated) following the onset of solvent production, and then quickly decreased to a lower level (but is still 7-fold higher than that at time point A) (Figure 4B).

$\sigma^{\mathrm{E}}$ is the first mother cell-specific sigma factor in $B$. subtilis, and the expression of sigE begins about $2 \mathrm{~h}$ after the onset of sporulation [45]. In C. acetobutylicum, the expression of sigE operon (spoIIGA-sigE, CAC1694 and CAC1695) does not exceed 1.3-fold higher than that at the initiation of fermentation [5]. In the case of C. beijerinckii, the expression of sigE operon (spoIIGA-sigE, Cbei_1119 and Cbei_1120) was up-regulated around 20fold at time point $\mathrm{C}$, and then decreased by 3 - to 6 -fold during late stationary phase (Figure $4 \mathrm{~B}$ ).
$\sigma^{G}$ is a forespore-specific sigma factor and it is active after complete engulfment of the forespore by the mother cell [46]. In B. subtilis, significant expression of sig $G$ begins 150 to $210 \mathrm{~min}$ after the onset of sporulation [47]. In the experiment presented here, the expression of $\operatorname{sig} G$ was up-regulated by 28.3 -fold at time point $\mathrm{C}$, and kept at high levels throughout the stationary process. More than 80 genes in B. subtilis which are related to spore protection and maturation were identified to be regulated by $\sigma^{G}[48,49]$. Among them, spoIVB is the gene encoding a signal protein for activating the lateracting sigma factor $\sigma^{\mathrm{K}}$ in the mother cell [50]; spoVA operon (spoVAA-AE) is a cluster of sporulation genes downstream of the sigF operon associated with dipicolinic acid transport into the developing spores $[51,52]$. In many clostridium species, spoVAC, $A D, A E$ were found at the same locus, but spoVAA and $A B$ are absent [53]. This is also the case for $C$. beijerinckii 8052, and spo$V A C, A D, A E$ (Cbei_815-817) were found to be organized in a single operon based on RNA-Seq data [19]. The expression of spoIVB and the spoVA operon was induced after the onset of high expression of $\operatorname{sig} G$, and peaked at time points D and E (around 4- to 16-fold higher than that at time point A). The expression profiles of $\operatorname{sig} G$ and the putative $\sigma^{\mathrm{G}}$-regulated genes well confirmed their regulation manner in C. beijerinckii (Figure 4B).

Sporulation regulation factors genes sigE and $\operatorname{sig} G$ in C. beijerinckii in the present study were induced and upregulated $>20$-fold right after the onset of sporulation. While in C. acetobutylicum, no active expression of sigE and $\operatorname{sigG}$ was detected up to $7.5 \mathrm{~h}$ after the onset of sporulation [5]. This dissimilarity coincides with the fact that forespores and endspores develop more rapidly in C. beijerinckii 8052 than in C. acetobutylicum 824 $[5,10]$.

In B. subtilis, sigK gene is expressed from a $\sigma^{\mathrm{E}}$-dependent promoter, and regulated by another transcription factor spoIIID [54-56]. The sigK gene is first expressed as an inactive pro- $\sigma^{\mathrm{k}}$ factor, and then cleaved to activate by a membrane-localized protease, SpoIVFB, whose activity is induced by SpoIVB, the signaling protein produced in the forespore $[57,58]$. The sigK gene in most clostridial species was also found to encode a pro- $\sigma^{\mathrm{k}}$ factor, and spoIVFB and spoIVB were identified in most clostridial species [53]. The product of Cbei_0501 (annotated as peptidase M50) in C. beijerinckii exhibits $36 \%$ amino acid identity (99 out of 273 ) and $62 \%$ positive (169 out of 273) to SpoIVFB in C. acetobutylicum by BLASTP. The expression of spoIIID (Cbei_0424) and sigK (Cbei_1115) was induced unexpectedly early at time point $B$, and increased up to 5.6- and 24.1-fold respectively at time point $\mathrm{D}$ (compared to time point B). Afterwards, both genes maintained at high expression levels. Nevertheless, significant expression of Cbei_0501 (putative spoIVFB) 
was only observed at time point $\mathrm{C}$, and then the expression decreased to a lower level (Figure 4B).

In B. subtilis, $a b r B$ encodes a transition state regulator, whose transcription depression by Spo0A leads to a burst of $\sigma^{\mathrm{H}}$ synthesis at the initiation of sporulation [59]. Maximal expression of $a b r B$ in B. subtilis was observed $2 \mathrm{~h}$ before the onset of sporulation [60]. In C. acetobutylicum, three $a b r B$ homologs (CAC0310, 1941 and 3647) were identified [61], among which CAC0310 was suggested as the putative true transitional-state regulator [62]. However, the decrease of expression of CAC0310 was not observed at initiation of sporulation but the highest expression was observed after the onset of sporulation during a time course transcriptional analysis for the wild type C. acetobutylicum 824 [5]. In C. beijerinckii 8052, six loci were annotated as genes encoding AbrB family transcriptional regulator. Among them, expression of three (Cbei_2219, Cbei_2270 and Cbei_3199) are not detectable most of the time. Expression of Cbei_0088 decreased temporally by 10.8 -fold at time point $\mathrm{B}$, but up-regulated back to even higher levels afterwards. The expression of Cbei_3375 was significantly depressed at time point C (10.5-fold from point B), and kept at low levels during the stationary phase. Although Cbei_4885 was down-regulated by 3.2 -fold at time point $C$, following expression was kept at relatively high levels and increased to a peak level at time point $\mathrm{F}$ (Figure 4B). In summary, none of the $a b r B$ genes in C. beijerinckii 8052 displayed exact antagonistic expression pattern to that of $s p o 0 H$. Whether there are $a b r B$ genes that play the similar role as $a b r B$ in $B$. subtilis warrants further study in respect that $s p o O H$ in this study had a very different transcriptional profile from that in B. subtilis.

As observed in other clostridium species, there was no orthologous phosphorelay system or sensory kinases in C. beijerinckii similar to those found in B. subtilis (KinA-KinE) for phosphorylating spo0A $[53,63]$. In C. acetobutylicum, it was suggested that the gene CAC3319 might act in a similar fashion to that of the sensory kinase genes in B. subtilis $[4,37]$. A recent study revealed evidence for two possible pathways for Spo0A activation in $C$. acetobutylicum, one dependent on CAC0323, and the other dependent on CAC0903 and CAC3319 [64]. In this study, with the time course transcriptional data, putative candidate proteins can be identified in C. beijerinckii that may play roles similar to sensory kinases for sporulation. Out of all the genes annotated as encoding sensory histidine kinases, ten were observed to be momentarily upregulated during the onset of sporulation (Figure 4B). Further molecular biology work focusing on specific genes needs to be carried out to define the genes that play the key roles in fermentation regulation.

\section{Cell motility genes}

The cell motility-related genes encode products responsible for chemotactic responses and flagellar assembly [65]. From the sequencing data, it was confirmed that a similar flagellar/chemotaxis multi-gene cluster exists in C. beijerinckii 8052 (Cbei_4312-4302) as that in C. acetobutylicum (CAC2225-2215) [19,66]. Motility-related genes in clostridia and bacilli are usually down-regulated in sporulation cells [39]. In this study, most genes in the flagellar/chemotaxis cluster were down-regulated by 2 - to 4 -fold at the onset of sporulation and were kept at lower expression levels thereafter. However, the last three genes at the end of the cluster (Cbei_4304-4302, encoding cheW, fliM and fliY, respectively) were initially down-regulated by 2 - to 3 fold at the onset of sporulation, and then unexpectedly increased during late stationary phase (Figure 4C).

There are several other genes in C. beijerinckii 8052 annotated as motility-related. Among them, Cbei_0755 (cheW) and Cbei_4958 (cheC) were active during exponential phase, and were down-regulated by 4.1- and 3.1-fold respectively after cells entered the stationary phase (time point D). Another cheW gene (Cbei_3954), on the other hand, exhibited an unexpected antagonistic pattern, which was strongly expressed throughout the entire stationary phase and peaked at time point $\mathrm{F}$ (Figure $4 \mathrm{C}$ ). The other chemotaxis genes were not active over the course of the fermentation process. The flagellar motility related genes $f \operatorname{lgB}$ (Cbei_4271) and flgC (Cbei_4270) were strongly expressed during exponential phase (time points $\mathrm{A}$ and $\mathrm{B}$ ), and down-regulated by 5.9- to 7.1-fold during the stationary phase. It has been reported that the expression of the flagellar/motility operon is negatively regulated by Spo0A in $B$ subtilis [38].

\section{Quorum sensing gene}

The gene luxS (Cbei_1237) encodes S-ribosylhomocysteinase, which produces autoinducers to function in the Luxs/AI-2 quorum sensing mechanism [67]. Maximal autoinducer activity was observed during mid-exponential phase in C. perfringens with autoluminesence assays [67], and the expression of luxS in C. acetobutylicum was found to be roughly proportional to cell density in a time-course transcriptional analysis of C. acetobutylicum 824 [5]. Sequence alignment of the protein encoded by the putative luxS gene in C. beijerinckii (Cbei_1237, $480 \mathrm{bp}$ ) and that in C. acetobutylicum (CAC2942, 477 bp) with BLASTP indicated that, out of 158 amino acids, there exists $74 \%$ identity (117 amino acids) and $84 \%$ positive (133 amino acids) matches. The expression of Cbei_1237 started at a high level during the acidogenesis phase, and then increased by 2.2 -fold and peaked during the transition to solventogenesis (time point $\mathrm{B}$ ), after which the expression decreased gradually to lower levels (Figure 4C). 


\section{Sugar transport genes}

The phosphoenolpyruvate-dependent phosphotransferase system (PTS) is the predominant sugar uptake pathway in C. beijerinckii [68]. The first two PTS domains (general PTS proteins), referred as EI (enzyme I) and HPr (heat stable, histidine-phosphorylatable protein), phosphorylate the sugar in the cytoplasm, which has been transported across the cell membrane from the extracellular side by substrate-specific enzyme II (EII) domains. Phosphorylated sugar is then able to enter the glycolytic pathway [68]. In C. beijerinckii, EI and HPr are encoded by Cbei_0196 (ptsI) and Cbei_1219 (ptsH) respectively. The expression of both genes was high throughout the fermentation process with a 2- to 3-fold decrease after onset of solventogenesis (Figure 4C). This agrees well with the previous finding that ATP-dependent glucose phosphorylation was predominant and phosphoenolpyruvate-dependent glucose phosphorylation was repressed during solventogenic stage for both C. beijerinckii 8052 and its mutant $C$. beijerinckii BA101 strains, although the latter exhibited a nearly 2-fold-greater ATP-dependent phosphorylation rate during solventogenic stage [69].

Previous competition studies indicated that glucose and mannose were assimilated by the same PTS in C. beijerinckii $[69,70]$. The mannose family PTS transporters are commonly found in gammaproteobacteria and firmicutes, including C. acetobutylicum and C. beijerinckii, and exhibit broad substrate specificity for glucose, mannose, sorbose, fructose, and a variety of other sugars $[10,71]$. In the gene cluster encoding for the mannose family PTS transporters, manIIAB encodes a membrane fusion protein of the IIA and IIB subunits involved in sugar phosphorylation, manIIC encodes a substrate-specific permease, and manIID encodes a mannose family-specific auxiliary protein (essential but of unknown function) [71]. The RNA-Seq data revealed that these three genes were organized in the same operon (Cbei_0711-0713) in C. beijerinckii 8052 [19], and the expression of manIIAB (Cbei_0711), manIIC (Cbei_0712) and manIID (Cbei_0713) was highly coordinated and unexpectedly up-regulated by 11.6, 20.4 and 31.6-fold respectively after onset of solventogenesis (Figure 4C).

There are 13 PTS domains identified in C. acetobutylicum, out of which six belongs to the glucose-glucoside (Glc) family [72]. Homologs were identified in C. beijerinckii for all the gene clusters encoding the Glc family PTS transporters in C. acetobutylicum. Among them, only Cbei_0751, Cbei_3273, Cbei_4532, Cbei_4533 and Cbei_4705 were actively expressed during the fermentation process, and Cbei_4533 (encoding N-acetylglucosaminespecific IIA subunit) and Cbei_4532 (encoding N-acetylglucosamine-specific IIBC subunit) were especially strongly expressed throughout the batch fermentation process (Figure 4C). By comparing the expression dynamics of gene clusters encoding for the Glc family PTS transporters and those for the mannose family PTS transporters, it could be inferred that the Glc family PTS transporters (especially those encoded by Cbei_4532 and _4533) play important roles during exponential and early stationary phases, while the mannose family PTS transporters may be more closely related to stationary and sporulation events.

\section{Self-organizing maps (SOM) analysis of functional groups}

SOM analysis was employed to investigate the global expression patterns, especially for genes belonging to specific COG categories across the genome (Figure 5) [5]. The expression of genes in clusters $C 2$ and $C 3$ was upregulated during early exponential-growth phase and decreased to lower levels afterwards. While these two clusters jointly contain 605 genes $(12.1 \%$, out of totally 5018 in the analysis), they are enriched with $49.2 \%$ of the genes related to translation (COG J), and $28.1 \%$ of genes related to cell motility (COG N). Cell motility genes were also over-represented by $14.8 \%$ in cluster $\mathrm{C} 1$, where the expression levels of genes were lower in the stationary phase than that in the exponential phase.

\section{Carbohydrate transport and metabolism (COG G)}

Nine of the glycolysis genes discussed above (Figure 4A) falls into clusters $\mathrm{C} 1$ and $\mathrm{C} 2$, indicating more active glycolytic activities during the exponential-growth phase. On the other hand, solventogenic clostridia initiate granulose production at the early stationary phase; Granulose is a glycogen-like polymer used by bacteria for energy storage under severe environments [74]. Operon prediction for $C$. acetobutylicum indicated that glgC (CAC2237, encoding glucose-1-phosphate adenylyltransferase), glgD (CAC2238, encoding ADP-glucose pyrophosphorylase), glgA (CAC2239, encoding glycogen synthase) and CAC2240 (encoding cyclomaltodextrin glucanotransferase domain-containing protein) express as a single transcript [66]. In addition, $g \lg P$ encodes a granulose phosphorylase (CAC1664, functions to depolymerize granulose), and $\operatorname{csr} A(C A C 2209)$ encodes a putative carbon storage regulator, which was reported to repress the expression of both $\operatorname{glg} A$ and $\operatorname{glg} P$ in Escherichia coli $[5,75]$. In C. beijerinckii 8052, it was observed that $g \operatorname{lgC}$ (Cbei_4905) and glgD (Cbei_4904) were organized in a operon, while the gene encoding 1,4-alpha-glucan branching enzyme (Cbei_4909), glgA (Cbei_4908), glgP (Cbei_4907) and the gene encoding the catalytic region of alpha amylase (Cbei_4906) were organized in another adjacent operon [19]. Cbei_4295 was annotated as the $\operatorname{csr} A$ gene. The five putative granulose formation genes (Cbei_4905-4909) in C. beijerinckii 8052 were grouped into cluster C6 based on their expression profiles (Figure 5). Expression of most granulose formation genes were up-regulated by 2- to 4-fold at transition phase from acidogenesis to solventogenesis (time point B) and maintained at high expression levels 


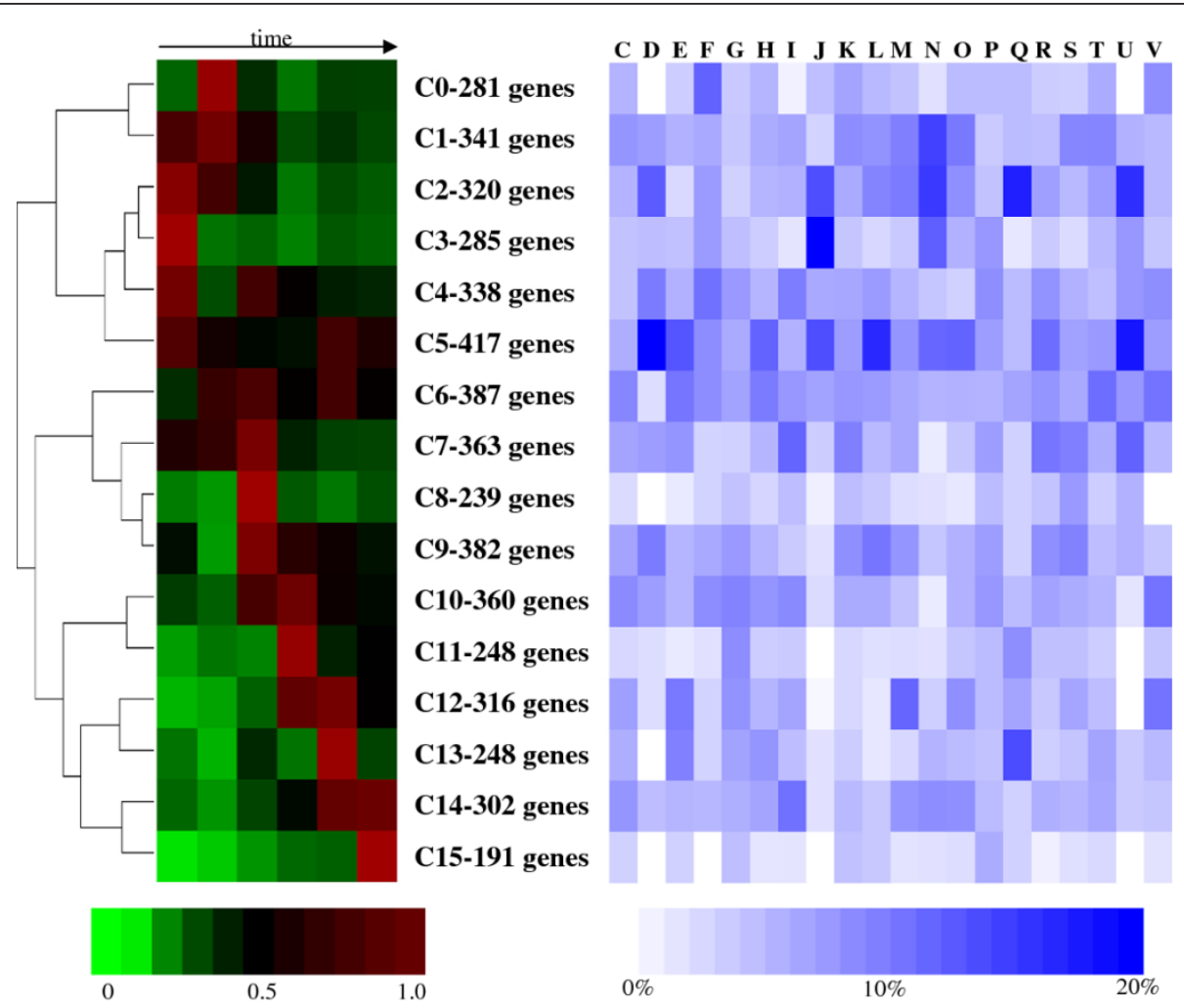

Figure 5 SOM clusters of gene expression profiles during the batch fermentation. SOM clusters are grouped by average-linkage hierarchical clustering based on expression pattern similarities. Distribution of COG categories across the clusters is represented colorimetrically on the right. COG functional groups are from the C. beijerinckii 8052 genome annotation defined by the COG database [73].

over the stationary phase (point C-E) (Figure 4C). Notwithstanding, the expression of $\operatorname{csr} A$ (Cbei_4295) was only detectable at A, C and F, which was much lower than those of the other granulose formation genes (Figure $4 \mathrm{C}$ ). It is not yet clear whether the $\operatorname{csr} A$ gene in $C$. beijerinckii functions similarly to that in E. coli.

\section{Translation genes (COG J)}

There are 181 translation-related genes included in the SOM analysis. The majority were grouped in the clusters where the gene expression is active during exponential phase (78\% enriched in $\mathrm{C} 1-\mathrm{C} 5$ ). There are 58 genes in C. beijerinckii genome encoding ribosomal proteins. Out of the 56 genes encoding ribosomal proteins included in the SOM analysis, 46 were clustered in $\mathrm{C} 3$, indicating that the protein synthesis machinery in the cell is mostly active during the early exponential phase (Figure 5). Similar results were reported for $C$. acetobutylicum, where most of the ribosomal protein genes were down-regulated at least 3-fold in stationary phase [5].

\section{Signal transduction mechanisms genes (COG T)}

There are 371 genes (around $7.4 \%$ of all genes) annotated as signal transduction related genes in C. beijerinckii. SOM analysis did not reveal any specific enriched clusters for these genes. However, they are slightly over- represented in cluster $\mathrm{C} 0$ and $\mathrm{C} 1$ (jointly $16 \%$ of category $\mathrm{T})$, where the expression levels are higher during the exponential phase (Figure 5). Among them, there are important cell chemotaxis and motility associated sensory transduction genes (Cbei_0279,_0665,_0755,_0804,_4012,_4161, _4307,_4309,_4310,_4466,_4604 and _4832). The expression of genes in clusters C8-C10 was momentarily up-regulated at onset of stationary phase and decreased quickly afterwards (Figure 5). The signal transduction genes in clusters C8-C10 may represent important signal transducers for solventogenesis and sporulation events. Among them, there are genes encoding response regulator receiver proteins, integral membrane sensor signal transduction histidine kinase and two-component transcriptional regulators (Additional file 4: Table S4) [76,77].

\section{Correlations of RNA-Seq and $q R T-P C R$}

The expression measurement with RNA-Seq approach was validated using qRT-PCR for selected genes. For all the selected genes, the dynamic gene expression profiles over time measured with RNA-Seq have very similar patterns as those measured with qRT-PCR (Additional file 5: Figure S1). We previously showed that good correlation exists between the overall gene expression quantification with RNA-Seq and that obtained with microarray or 
qRT-PCR [19]. These results demonstrate that RNA-Seq is an effective approach for quantification of gene expression.

Previously, Shi and Blaschek reported the transcriptional analysis of $C$. beijerinckii using a ca. 500-gene set DNA microarray where only the expression of genes orthologous to those previously found to be important to the physiology of $C$. acetobutylicum 824 was examined [10]. In this study, employing RNA-Seq technology, for the first time the genome-wide dynamic transcriptional profiling of C. beijerinckii correlated with the physiological activities over the course of fermentation process has been revealed with a much larger dynamic range. In addition, single-nucleotide resolution RNA-Seq data also revealed the transcriptome structural organization of C. beijerinckii 8052 in depth [19]. The transcriptome structural information together with the genome-wide dynamic transcriptional profiling can provide essential references for further improvement of C. beijerinckii strains by employing system biology-based strategies and metabolic engineering approaches. Furthermore, the genome-wide RNA-Seq analysis also disclosed the different expression dynamics of many allelic genes in the genome of C. beijerinckii 8052, which provided important insight for future studies on the properties of potential isoenzymes and their associated functions during specific fermentation stages.

\section{Conclusions}

By employing single-base resolution RNA-Seq technology, the genome-wide transcriptional dynamics of C. beijerinckii 8052 throughout the course of a batch fermentation was revealed in great depth. RNA-Seq technology can not only quantify the differential transcription of specific genes over time, but is also able to compare transcription levels of different genes in the same sample. Overall dynamic transcription profiles demonstrated obvious temporal variation trend throughout the fermentation, corresponding to the physiological state change of the cells. Glycolysis genes demonstrated higher expression during acidogenesis phase. The expression of acid formation genes declined at the onset of solvent formation, in accordance with the metabolic pathway shift from acidogenesis to solventogenesis. The sol operon, including $a d c$ as a part, was up-regulated at the onset of solventogenesis and maintained at high levels through the stationary phase. Most sporulation genes in C. beijerinckii 8052 demonstrated similar temporal expression patterns to those observed in B. subtilis and $C$. acetobutylicum, while sporulation sigma factor genes $\operatorname{sig} E$ and $\operatorname{sig} G$ exhibited accelerated and stronger expression in C. beijerinckii 8052, consistent with the more rapid forespore and endspore development in this strain. The PTS transport system encoding genes were highly expressed during acidogenesis and declined 2- to 3 -fold after entering solventogenesis phase, agreeing well with the report that ATP-dependent glucose phosphorylation was predominant and phosphoenolpyruvatedependent PTS was repressed during solventogenic stage for C. beijerinckii. Finally, SOM and clustering analysis revealed that genes of specific COG functional classes demonstrated global gene expression patterns corresponding to the cell physiological change and fermentation pathway switch.

\section{Methods}

\section{Bacterial culture and fermentation experiment}

Laboratory stocks of $C$. beijerinckii 8052 spores were stored in sterile $\mathrm{H}_{2} \mathrm{O}$ at $4^{\circ} \mathrm{C}$ [78]. Spores were heatshocked at $80^{\circ} \mathrm{C}$ for $10 \mathrm{~min}$, followed by cooling on ice for $5 \mathrm{~min}$. The heat-shocked spores were inoculated at a $1 \%$ inoculum level into tryptone-glucose-yeast extract (TGY) medium containing $30 \mathrm{~g} \mathrm{~L}^{-1}$ tryptone, $20 \mathrm{~g} \mathrm{~L}^{-1}$ glucose, $10 \mathrm{~g} \mathrm{~L}^{-1}$ yeast extract and $1 \mathrm{~g} \mathrm{~L}^{-1} \mathrm{~L}$-cysteine. The TGY culture was incubated at $35 \pm 1^{\circ} \mathrm{C}$ for $12-14 \mathrm{~h}$ in an anaerobic chamber under $\mathrm{N}_{2}: \mathrm{CO}_{2}: \mathrm{H}_{2}$ (volume ratio of $85: 10: 5)$ atmosphere. Subsequently, actively growing culture was inoculated into a model solution containing $60 \mathrm{~g} \mathrm{~L}^{-1}$ glucose, $1 \mathrm{~g} \mathrm{~L}^{-1}$ yeast extract, and filter-sterilized P2 medium [79] in a Sixfors bioreactor system (Infors AG, Bottmingen, Switzerland). Oxygen-free nitrogen was flushed through the broth to initiate anaerobiosis until the culture initiated its own gas production $\left(\mathrm{CO}_{2}\right.$ and $\mathrm{H}_{2}$ ). Temperature was controlled at $35 \pm 1^{\circ} \mathrm{C}$. A stirring at $50 \mathrm{rpm}$ was employed for mixing. Cell density and product concentration were monitored through the course of fermentation. For sequencing purpose, samples were taken over the early exponential, late exponential and stationary phases (samples A-F at 2, 4.5, 10, 14, 17 and $26.5 \mathrm{~h}$ respectively as shown in Figure $1 \mathrm{~A}$ ).

\section{Culture growth and fermentation products analysis}

Culture growth was measured by following optical density (OD) in the fermentation broth at $\mathrm{A}_{600}$ using a BioMate 5 UV-vis Spectrophotometer (Thermo Fisher Scientific Inc., Waltham, MA). ABE, acetic acid, and butyric acid concentrations were quantified using gas chromatography (GC) system as previously described [79].

\section{RNA isolation, library construction and sequencing}

For RNA isolation, $10 \mathrm{ml}$ cultures were harvested at each time point, and centrifuged at $4,000 \times \mathrm{g}$ for $10 \mathrm{~min}$ at $4{ }^{\circ} \mathrm{C}$. Total RNA was extracted from the cell pellet using Trizol reagent based on manufacture's protocol (Invitrogen, Carlsbad, CA) and further purified using RNeasy mini kit (Qiagen, Valencia, CA). DNA was removed using a DNAfree ${ }^{\mathrm{TM}}$ kit (Ambion Inc., Austin, TX). RNA quality was assessed using a 2100 bioanalyzer (Agilent Technologies, 
Santa Clara, CA). RNA concentration was determined with a nanodrop (Biotek Instruments, Winooski, VT). Bacterial $16 \mathrm{~S}$ and $23 \mathrm{~S}$ ribosomal RNAs were removed with a MICROBExpress ${ }^{\mathrm{TM}}$ kit (Ambion Inc., Austin, TX). The enriched mRNA was converted to a RNA-Seq library using the mRNA-Seq library construction kit (Illumina Inc., San Diego, CA) following manufacturer's protocols. For samples A to F, two samples were pooled and sequenced on one single lane of an eight-lane flow cell with the Genome Analyzer IIx system (Illumina Inc., San Diego, CA). However, sample F yielded a poor read quality following the first sequencing. In order to obtain enough sequencing depth, sample F was sequenced again using one single lane under otherwise identical conditions. The derived sequence reads were $75 \mathrm{nt}$ long. The overall error rate of the control DNA was $<0.6 \%$. The total number of reads generated from each library is summarized in Table 1.

\section{RNA-Seq data analysis}

The generated 75-nt reads were mapped to the $C$. beijerinckii 8052 genome using MAQ, and those that did not align uniquely to the genome were discarded [80]. The quality parameter $(-\mathrm{q})$ used in MAQ pileup was set to 30 . Each base was assigned a value based on the number of mapped sequence coverage. The quantitative gene expression value, RPKM (reads/Kb/Million), was calculated using custom Perl scripts by normalizing the sequence coverage over the gene length and total unambiguously mapped reads in each library $[13,18]$.

$\mathrm{Z}$ score was calculated as $\mathrm{Z}=\left(\mathrm{X}-\mathrm{X}_{\mathrm{av}}\right) / \mathrm{X}_{\mathrm{SD}}$. $\mathrm{X}$ is the $\log _{2^{-}}$ transformed RPKM value for a given gene in a specific sample, $X_{\mathrm{av}}$ is the mean of $\log _{2}$-transformed RPKM values for that gene in all six samples, and $\mathrm{X}_{\mathrm{SD}}$ is the standard deviation of $\log _{2}$-transformed RPKM for that gene across all samples [18,21].

The gene expression results were visualized colorimetrically using heatmap plots. $\mathrm{R}$ language and the open source software Bioconductor based on $\mathrm{R}$ were used for the data analysis and plots [81-83]. Specifically, functions in Heatplus package in Bioconductor and the $\mathrm{R}$ package gplots were employed for constructing the heatmap plots. Time course RPKM values were first transformed to $\log _{2}$-scale. The $\log _{2}$-transfromed RPKM values were then properly centered for better representation of the data by the heatmap plots. More details about this method were summarized in the Additional file 6.

\section{Self-organizing maps (SOM) analysis}

Global gene expression patterns were analyzed with selforganizing maps (SOM) analysis [5]. The RPKM value of a gene at each time point was first divided by the square root of the sum of the squares of the gene's RPKM values at all six time points, and therefore the sum of the squares of each gene's standardized ratios within the experiment is 1 . The preprocessed gene expression values were then standardized and grouped into $16 \mathrm{SOM}$ clusters based on the expression pattern similarity (Figure 5). In order to examine the SOM clusters for enriched Clusters of Orthologous Groups of proteins (COG), the frequency at which the genes in each cluster fell in every COG category was calculated and plotted colorimetrically (Figure 5). If one gene belongs to more than one COG categories, the gene was counted once for each category [5]. Data were processed and visualized with Gene Cluster 3.0 [84] and the SOMClustering and Java TreeView packages in GenePattern [85].

\section{Real time qRT-PCR}

Quantitative reverse transcription PCR (qRT-PCR) was performed for selected genes in order to validate the quantification of gene expression levels obtained by RNA-Seq. Nine genes that are important involved in the central pathways for glycolysis, acidogenesis and solventogenesis were chosen for the examination. Cbei_2428 was used as the endogenous control gene based on its relatively constant expression levels throughout the fermentation process as discussed earlier. Specific primer sequences for tested genes are listed in Additional file 7: Table S5. Triplicate reactions were performed using Power SYBR green PCR master mix (Applied Biosystems, Carlsbad, CA) on an ABI Prism 7900HT fast real-time PCR machine (Applied Biosystems). The normalized threshold value $(\Delta \mathrm{Ct})$ of each gene along time course was compared to that of the same gene at the first time point (time point A in Figure 1A).

\section{RNA-Seq data accession number}

The RNA-Seq sequencing data have been deposited in the NCBI Sequence Read Archive (SRA) under the accession number SRA045799.

\section{Additional material}

Additional file 1: The genes with Z-score $>1.7$ in each sample.

Additional file 2: The top 100 highest expressed genes in samples $B$ and D.

Additional file 3: The expression of the putative alcohol dehydrogenase genes in C. beijerinckii 8052 .

Additional file 4: The putative signal transduction genes in SOM clusters C8-C10 in C. beijerinckii 8052.

Additional file 5: The qRT-PCR verification of RNA-Seq quantification results for selected genes. The fold change of each gene's expression along time course measured by either qRT- PCR (in black) or RNA-Seq (in red) was compared to that of the same gene at first time point (time point A in Figure 1A). (A) Cbei_4852, pfk. (B) Cbei_1903, fba. (C) Cbei_4851, pyk. (D) Cbei_0203, ptb. (E) Cbei_0204, buk. (F) Cbei_3833, ctfA. (G) Cbei_3834, ctfB. (H) Cbei_0411, th/A. (I) Cbei_0325, hbd. 
Additional file 6: RNA-Seq data analysis.

Additional file 7: Genes and primer sequences for qRT-PCR test.

\section{Acknowledgements}

This work was supported by USDA Research Initiative Award AG 2006-3550417419, Illinois Council on Food and Agricultural Research (C-FAR) Grant 698 IDA CF06DS-01-03 and Department of Energy (DOE) grant \#2011-01219 to HPB. The authors thank for Dr. Roderick I. Mackie for advice during the planning, execution and analysis of the experiments described herein. The authors also thank Dr. Heng Li and Dr. Timothy Perkins for their helpful inputs on the data analysis.

\section{Author details}

'Department of Agricultural and Biological Engineering, University of Illinois at Urbana-Champaign, Urbana, IL 61801, USA. ${ }^{2}$ Institute for Genomic Biology, University of Illinois at Urbana-Champaign, Urbana, IL 61801, USA.

${ }^{3}$ Department of Animal Sciences, University of Illinois at Urbana-Champaign, Urbana, IL 61801, USA. ${ }^{4}$ Chengdu Institute of Biology, Chinese Academy of Sciences, Chengdu Sichuan 610041, China. ${ }^{5}$ Department of Food Science and Human Nutrition, University of Illinois at Urbana-Champaign, Urbana, IL 61801, USA. ${ }^{6}$ Center for Advanced Bioenergy Research (CABER), University of Illinois at Urbana-Champaign, Urbana, IL 61801, USA.

\section{Authors' contributions}

YW, XL, HPB conceived and designed the study. YW and XL performed the experiments. $Y W, X L$ and $Y M$ analyzed the RNA-Seq data. $Y W, X L$ and HPB wrote the manuscript, with input from all authors. All authors discussed the results, read and approved the final manuscript.

\section{Competing interests}

The authors declare that they have no competing interests.

Received: 10 November 2011 Accepted: 20 March 2012

Published: 20 March 2012

\section{References}

1. Dürre P: Biobutanol: an attractive biofuel. Biotechnol f 2007, 2(12):1525-1534

2. Ezeji T, Blaschek HP: Fermentation of dried distillers' grains and solubles (DDGS) hydrolysates to solvents and value-added products by solventogenic clostridia. Bioresour Technol 2008, 99(12):5232-5242.

3. Alsaker KV, Spitzer TR, Papoutsakis ET: Transcriptional analysis of spoOA overexpression in Clostridium acetobutylicum and its effect on the cell's response to butanol stress. J Bacteriol 2004, 186(7):1959-1971.

4. Tomas CA, Beamish J, Papoutsakis ET: Transcriptional analysis of butanol stress and tolerance in Clostridium acetobutylicum. J Bacterio/ 2004, 186(7):2006-2018.

5. Alsaker KV, Papoutsakis ET: Transcriptional program of early sporulation and stationary-phase events in Clostridium acetobutylicum. J Bacteriol 2005, 187(20):7103-7118.

6. Alsaker KV, Paredes CJ, Papoutsakis ET: Design, optimization and validation of genomic DNA microarrays for examining the Clostridium acetobutylicum transcriptome. Biotechnol Bioprocess Eng 2005, 10(5):432-443.

7. Jones SW, Paredes CJ, Tracy B, Cheng N, Sillers R, Senger RS, Papoutsakis ET: The transcriptional program underlying the physiology of clostridial sporulation. Genome Biol 2008, 9(7):R114.

8. Alsaker KV, Paredes C, Papoutsakis ET: Metabolite stress and tolerance in the production of biofuels and chemicals: gene-expression-based systems analysis of butanol, butyrate, and acetate stresses in the anaerobe Clostridium acetobutylicum. Biotechnol Bioeng 2010, 105(6):1131-1147.

9. Janssen H, Doring C, Ehrenreich A, Voigt B, Hecker M, Bahl H, Fischer RJ: A proteomic and transcriptional view of acidogenic and solventogenic steady-state cells of Clostridium acetobutylicum in a chemostat culture. Appl Microbiol Biotechnol 2010, 87(6):2209-2226.

10. Shi Z, Blaschek HP: Transcriptional analysis of Clostridium beijerinckii NCIMB 8052 and the hyper-butanol-producing mutant BA101 during the shift from acidogenesis to solventogenesis. Appl Environ Microbiol 2008, 74(24):7709-7714.

11. Passalacqua KD, Varadarajan A, Ondov BD, Okou DT, Zwick ME, Bergman NH: Structure and complexity of a bacterial transcriptome. $J$ Bacteriol 2009, 191(10):3203-3211.

12. Perkins TT, Kingsley RA, Fookes MC, Gardner PP, James KD, Yu L, Assefa SA, He M, Croucher NJ, Pickard DJ, et al: A strand-specific RNA-Seq analysis of the transcriptome of the typhoid bacillus Salmonella typhi. PLoS Genet 2009, 5(7):e1000569.

13. Mortazavi A, Williams BA, McCue K, Schaeffer L, Wold B: Mapping and quantifying mammalian transcriptomes by RNA-Seq. Nat Methods 2008, 5(7):621-628.

14. Nagalakshmi U, Wang Z, Waern K, Shou C, Raha D, Gerstein M, Snyder M: The transcriptional landscape of the yeast genome defined by RNA sequencing. Science 2008, 320:1344-1349.

15. van Vliet AHM: Next generation sequencing of microbial transcriptomes: challenges and opportunities. FEMS Microbiol Lett 2010, 302(1):1-7.

16. Wang Z, Gerstein M, Snyder M: RNA-Seq: a revolutionary tool for transcriptomics. Nat Rev Genet 2009, 10(1):57-63.

17. Legendre M, Audic S, Poirot O, Hingamp P, Seltzer V, Byrne D, Lartigue A, Lescot M, Bernadac A, Poulain J, et al: mRNA deep sequencing reveals 75 new genes and a complex transcriptional landscape in Mimivirus. Genome Res 2010, 20(5):664-674.

18. Severin A, Woody J, Bolon Y-T, Joseph B, Diers B, Farmer A, Muehlbauer G, Nelson R, Grant D, Specht J, et al: RNA-Seq Atlas of Glycine max: a guide to the soybean transcriptome. BMC Plant Biol 2010, 10(1):160.

19. Wang Y, Li X, Mao Y, Blaschek H: Single-nucleotide resolution analysis of the transcriptome structure of Clostridium beijerinckii NCIMB 8052 using RNA-Seq. BMC Genomics 2011, 12:479.

20. Hill MO, Gauch HG: Detrended correspondence analysis: an improved ordination technique. Vegetatio 1980, 42(1-3):47-58.

21. Benedito VA, Torres-Jerez I, Murray JD, Andriankaja A, Allen S, Kakar K, Wandrey $\mathrm{M}$, Verdier J, Zuber $\mathrm{H}, \mathrm{Ott} \mathrm{T}$, et al: A gene expression atlas of the model legume Medicago truncatula. Plant J 2008, 55(3):504-513.

22. Winzer K, Lorenz K, Zickner B, Dürre P: Differential regulation of two thiolase genes from Clostridium acetobutylicum DSM 792. J Mol Microbiol Biotechnol 2000, 2(4):531-541.

23. Grimmler $C$, Janssen $H$, Krausse $D$, Fischer RJ, Bahl H, Dürre $P$, Liebl W, Ehrenreich A: Genome-wide gene expression analysis of the switch between acidogenesis and solventogenesis in continuous cultures of Clostridium acetobutylicum. J Mol Microbiol Biotechnol 2011, 20(1):1-15.

24. Cornillot E, Nair RV, Papoutsakis ET, Soucaille P: The genes for butanol and acetone formation in Clostridium acetobutylicum ATCC 824 reside on a large plasmid whose loss leads to degeneration of the strain. J Bacteriol 1997, 179(17):5442-5447.

25. Gerischer U, Dürre P: Cloning, sequencing, and molecular analysis of the acetoacetate decarboxylase gene region from Clostridium acetobutylicum. J Bacteriol 1990, 172(12):6907-6918.

26. Petersen DJ, Cary JW, Vanderleyden J, Bennett GN: Sequence and arrangement of genes encoding enzymes of the acetone-production pathway of Clostridium acetobutylicum ATCC 824. Gene 1993, 123(1):93-97.

27. Gerischer U, Dürre P: mRNA analysis of the adc gene region of Clostridium acetobutylicum during the shift to solventogenesis. J Bacteriol 1992, 174(2):426-433.

28. Feustel L, Nakotte S, Dürre P: Characterization and development of two reporter gene systems for Clostridium acetobutylicum. Appl Environ Microbiol 2004, 70(2):798-803.

29. Sauer U, Dürre P: Differential induction of genes related to solvent formation during the shift from acidogenesis to solventogenesis in continuous culture of Clostridium acetobutylicum. FEMS Microbiol Lett 1995, 125(1):115-120

30. Chen J-S: Alcohol dehydrogenase: multiplicity and relatedness in the solvent-producing clostridia. FEMS Microbiol Rev 1995, 17(3):263-273.

31. Walter KA, Bennett GN, Papoutsakis ET: Molecular characterization of two Clostridium acetobutylicum ATCC 824 butanol dehydrogenase isozyme genes. J Bacteriol 1992, 174(22):7149-7158

32. Welch RW, Rudolph FB, Papoutsakis ET: Purification and characterization of the NADH-dependent butanol dehydrogenase from Clostridium acetobutylicum (ATCC 824). Arch Biochem Biophys 1989, 273(2):309-318. 
33. Predich $M$, Nair G, Smith I: Bacillus subtilis early sporulation genes kinA, spoOA, and spoOF are transcribed by the RNA polymerase containing $\sigma^{\mathrm{H}}$. J Bacteriol 1992, 174(9):2771-2778.

34. Dürre $P$, Hollergschwandner $C$ : Initiation of endospore formation in Clostridium acetobutylicum. Anaerobe 2004, 10(2):69-74.

35. Wilkinson SR, Young DI, Gareth Morris J, Young M: Molecular genetics and the initiation of solventogenesis in Clostridium beijerinckii (formerly Clostridium acetobutylicum) NCIMB 8052. FEMS Microbiol Rev 1995, 17(3):275-285

36. Harris LM, Welker NE, Papoutsakis ET: Northern, morphological, and fermentation analysis of 5 POOA inactivation and overexpression in Clostridium acetobutylicum ATCC 824. J Bacteriol 2002, 184(13):3586-3597.

37. Tomas CA, Alsaker KV, Bonarius HPJ, Hendriksen WT, Yang H, Beamish JA, Paredes CJ, Papoutsakis ET: DNA array-based transcriptional analysis of asporogenous, nonsolventogenic Clostridium acetobutylicum strains SKO1 and M5. J Bacteriol 2003, 185(15):4539-4547.

38. Molle V, Fujita M, Jensen ST, Eichenberger P, Gonzalez-Pastor JE, Liu JS, Losick R: The Spo0A regulon of Bacillus subtilis. Mol Microbiol 2003, 50(5):1683-1701.

39. Paredes CJ, Alsaker KV, Papoutsakis ET: A comparative genomic view of clostridial sporulation and physiology. Nat Rev Microbiol 2005, 3(12):969-978.

40. Ravagnani A, Jennert KCB, Steiner E, Grunberg $R$, Jefferies JR, Wilkinson SR, Young DI, Tidswell EC, Brown DP, Youngman P, et al: Spo0A directly controls the switch from acid to solvent production in solvent-forming clostridia. Mol Microbiol 2000, 37(5):1172-1185.

41. Heap JT, Kuehne SA, Ehsaan M, Cartman ST, Cooksley CM, Scott JC, Minton NP: The ClosTron: Mutagenesis in Clostridium refined and streamlined. J Microbiol Methods 2010, 80(1):49-55.

42. Losick R, Stragier P: Crisscross regulation of cell-type-specific gene expression during development in B. subtilis. Nature 1992, 355(6361):601-604

43. Arigoni F, Duncan L, Alper S, Losick R, Stragier P: SpollE governs the phosphorylation state of a protein regulating transcription factor $\sigma^{F}$ during sporulation in Bacillus subtilis. Proc Natl Acad Sci USA 1996, 93(8):3238-3242.

44. York K, Kenney TJ, Satola S, Moran CP Jr, Poth H, Youngman P: Spo0A controls the $\sigma^{\mathrm{A}}$-dependent activation of Bacillus subtilis sporulationspecific transcription unit spollE. J Bacteriol 1992, 174(8):2648-2658.

45. Kenney TJ, Moran CP Jr: Organization and regulation of an operon that encodes a sporulation-essential sigma factor in Bacillus subtilis. J Bacteriol 1987, 169(7):3329-3339.

46. Cutting S, Panzer S, Losick R: Regulatory studies on the promoter for a gene governing synthesis and assembly of the spore coat in Bacillus subtilis. J Mol Biol 1989, 207(2):393-404.

47. Sun DX, Cabrera-Martinez RM, Setlow P: Control of transcription of the Bacillus subtilis spolllG gene, which codes for the forespore-specific transcription factor $\sigma^{\mathrm{G}}$. J Bacteriol 1991, 173(9):2977-2984.

48. Steil L, Serrano M, Henriques AO, Volker U: Genome-wide analysis of temporally regulated and compartment-specific gene expression in sporulating cells of Bacillus subtilis. Microbiology-(UK) 2005, 151:399-420.

49. Wang ST, Setlow B, Conlon EM, Lyon JL, Imamura D, Sato T, Setlow P, Losick R, Eichenberger $P$ : The forespore line of gene expression in Bacillus subtilis. J Mol Biol 2006, 358(1):16-37.

50. Cutting S, Driks A, Schmidt R, Kunkel B, Losick R: Forespore-specific transcription of a gene in the signal transduction pathway that governs Pro- $\sigma^{\mathrm{K}}$ processing in Bacillus subtilis. Genes Dev 1991, 5(3):456-466.

51. Kunst F, Ogasawara N, Moszer I, Albertini AM, Alloni G, Azevedo V, Bertero MG, Bessieres P, Bolotin A, Borchert S, et al: The complete genome sequence of the Gram-positive bacterium Bacillus subtilis. Nature 1997, 390(6657):249-256.

52. Tovar-Rojo F, Chander M, Setlow B, Setlow P: The products of the spoVA operon are involved in dipicolinic acid uptake into developing spores of Bacillus subtilis. J Bacteriol 2002, 184(2):584-587.

53. Stragier P: A gene odyssey: exploring the genomes of endosporeforming bacteria. In Bacillus subtilis and its closest relatives: from genes to cells. Edited by: Sonenshein A, Hoch J, Losick R. Washington, DC: ASM Press; 2002:519-525.

54. Driks A, Losick R: Compartmentalized expression of a gene under the control of sporulation transcription factor $\sigma^{\mathrm{E}}$ in Bacillus subtilis. Proc Natl Acad Sci USA 1991, 88(22):9934-9938.
55. Kunkel B, Kroos L, Poth H, Youngman P, Losick R: Temporal and spatial control of the mother-cell regulatory gene spollID of Bacillus subtilis. Genes Dev 1989, 3(11):1735-1744.

56. Halberg $R$, Kroos L: Sporulation regulatory protein SpollID from Bacillus subtilis activates and represses transcription by both mother-cell-specific forms of RNA polymerase. J Mol Biol 1994, 243(3):425-436.

57. Lu S, Halberg R, Kroos L: Processing of the mother-cell $\sigma$ factor, $\sigma^{K}$, may depend on events occurring in the forespore during Bacillus subtilis development. Proc Natl Acad Sci USA 1990, 87(24):9722-9726.

58. Green DH, Cutting SM: Membrane topology of the Bacillus subtilis Pro- $\sigma^{\mathrm{K}}$ processing complex. J Bacteriol 2000, 182(2):278-285.

59. Weir J, Predich M, Dubnau E, Nair G, Smith I: Regulation of spoOH, a gene coding for the Bacillus subtilis $\sigma^{\mathrm{H}}$ factor. J Bacteriol 1991, 173(2):521-529.

60. Jiang $M$, Shao WL, Perego $M$, Hoch JA: Multiple histidine kinases regulate entry into stationary phase and sporulation in Bacillus subtilis. Mol Microbiol 2000, 38(3):535-542

61. Nolling J, Breton G, Omelchenko MV, Makarova KS, Zeng QD, Gibson R, Lee HM, Dubois J, Qiu DY, Hitti J, et al: Genome sequence and comparative analysis of the solvent-producing bacterium Clostridium acetobutylicum. J Bacteriol 2001, 183(16):4823-4838.

62. Scotcher MC, Rudolph FB, Bennett GN: Expression of $a b r B 310$ and $\sin R$, and effects of decreased $a b r B 310$ expression on the transition from acidogenesis to solventogenesis, in Clostridium acetobutylicu ATCC 824. Appl Environ Microbiol 2005, 71(4):1987-1995.

63. Stephenson K, Hoch JA: Evolution of signalling in the sporulation phosphorelay. Mol Microbiol 2002, 46(2):297-304.

64. Steiner $E$, Dago AE, Young DI, Heap JT, Minton NP, Hoch JA, Young M: Multiple orphan histidine kinases interact directly with Spo0A to control the initiation of endospore formation in Clostridium acetobutylicum. Mol Microbiol 2011, 80(3):641-654.

65. Wadhams GH, Armitage JP: Making sense of it all: bacterial chemotaxis. Nat Rev Mol Cell Biol 2004, 5(12):1024-1037.

66. Paredes CJ, Rigoutsos I, Papoutsakis ET: Transcriptional organization of the Clostridium acetobutylicum genome. Nucleic Acids Res 2004, 32(6):1973-1981.

67. Ohtani K, Hayashi H, Shimizu T: The luxS gene is involved in cell-cell signalling for toxin production in Clostridium perfringens. Mol Microbiol 2002, 44(1):171-179.

68. Mitchell Wilfrid J, Tangney M: Carbohydrate uptake by the phosphotransferase system and other mechanisms. In Handbook on clostridia. Edited by: Dürre P. London: CRC press; 2005:155-175.

69. Lee J, Blaschek HP: Glucose uptake in Clostridium beijerinckii NCIMB 8052 and the solvent-hyperproducing mutant BA101. Appl Environ Microbiol 2001, 67(11):5025-5031.

70. Mitchell WJ, Shaw JE, Andrews L: Properties of the glucose phosphotransferase system of Clostridium acetobutylicum NCIB 8052. Appl Environ Microbiol 1991, 57(9):2534-2539.

71. Barabote RD, Saier MH: Comparative genomic analyses of the bacterial phosphotransferase system. Microbiol Mol Biol Rev 2005, 69(4):608-634.

72. Mitchell WJ, Tangney M: Carbohydrate uptake by the phosphotransferase system and other mechanisms. In Handbook on clostridia. Edited by: Dürre P. London: CRC press; 2005:155-175.

73. Tatusov RL, Galperin MY, Natale DA, Koonin EV: The COG database: a tool for genome-scale analysis of protein functions and evolution. Nucleic Acids Res 2000, 28(1):33-36.

74. Reysenbach AL, Ravenscroft N, Long S, Jones DT, Woods DR: Characterization, biosynthesis, and regulation of granulose in Clostridium acetobutylicum. Appl Environ Microbiol 1986, 52(1):185-190.

75. Yang HH, Liu MY, Romeo T: Coordinate genetic regulation of glycogen catabolism and biosynthesis in Escherichia coli via the CsrA gene product. J Bacteriol 1996, 178(4):1012-1017.

76. Stock AM, Robinson VL, Goudreau PN: Two-component signal transduction. Annu Rev Biochem 2000, 69(1):183-215.

77. West $A H$, Stock AM: Histidine kinases and response regulator proteins in two-component signaling systems. Trends Biochem Sci 2001, 26(6):369-376.

78. Annous BA, Blaschek HP: Isolation and characterization of Clostridium acetobutylicum mutants with enhanced amylolytic activity. Appl Environ Microbiol 1991, 57(9):2544-2548.

79. Qureshi N, Lolas A, Biaschek HP: Soy molasses as fermentation substrate for production of butanol using Clostridium beijerinckii BA101. J Ind Microbiol Biotechnol 2001, 26(5):290-295. 
80. Li H, Ruan J, Durbin R: Mapping short DNA sequencing reads and calling variants using mapping quality scores. Genome Res 2008,

18(11):1851-1858.

81. Gentleman R, Carey V, Bates D, Bolstad B, Dettling M, Dudoit S, Ellis B, Gautier L, Ge Y, Gentry J, et al: Bioconductor: open software development for computational biology and bioinformatics. Genome Biol 2004, 5(10): R80.

82. Anders $\mathrm{S}$, Huber W: Differential expression analysis for sequence count data. Genome Biol 2010, 11(10):R106.

83. Robinson MD, McCarthy DJ, Smyth GK: edgeR: a Bioconductor package for differential expression analysis of digital gene expression data. Bioinformatics 2010, 26(1):139-140.

84. Eisen MB, Spellman PT, Brown PO, Botstein D: Cluster analysis and display of genome-wide expression patterns. Proc Natl Acad Sci USA 1998, 95(25):14863-14868.

85. Reich M, Liefeld T, Gould J, Lerner J, Tamayo P, Mesirov JP: GenePattern 2.0. Nature Genet 2006, 38(5):500-501.

doi:10.1186/1471-2164-13-102

Cite this article as: Wang et al: Genome-wide dynamic transcriptional profiling in clostridium beijerinckii NCIMB 8052 using single-nucleotide resolution RNA-Seq. BMC Genomics 2012 13:102.

\section{Submit your next manuscript to BioMed Central} and take full advantage of:

- Convenient online submission

- Thorough peer review

- No space constraints or color figure charges

- Immediate publication on acceptance

- Inclusion in PubMed, CAS, Scopus and Google Scholar

- Research which is freely available for redistribution

Submit your manuscript at www.biomedcentral.com/submit 